American Journal of Animal and Veterinary Sciences 5 (1): 40-44, 2010

ISSN $1557-4555$

(C) 2010 Science Publications

\title{
Ultrasonography and Radiography Evaluation of the Cartilage Graft in Repair of Experimentally Induced Radial Bone Defect in Rabbit
}

\author{
${ }^{1}$ Foad Sadi, ${ }^{1}$ Abbas Veshkini, ${ }^{2}$ Davood Sharifi and ${ }^{1} \mathrm{M}$ Nasroulahzadeh Masouleh \\ ${ }^{1}$ Sciences and Research Branch, Department of Radiology, \\ ${ }^{2}$ Sciences and Research Branch, Department of Surgery, \\ Faculty of Specialized Veterinary Sciences, Islamic Azad University, Punak, Tehran, Iran
}

\begin{abstract}
We would like to thank to the Faculty of Specialized Veterinary Sciences research council. Science and Research Branch of Islamic Azad University, Punak Tehran for approval and financial support to finish this project. Problems statement: The purpose of this research was to determine the biological effect of cartilage graft as a bone defect filler and osteogenetic stimulation to speed up bone healing too. Approach: Sixteen adult male New Zealand white rabbits having body weight ranged from 3.0-3.5 Kg. Under general anesthesia, a segmental full thickness bone defect of $10 \mathrm{~mm}$ in length was created in the middle of the right radial shaft in all rabbits. They were divided into two groups of 6 rabbits each. Group I was considered as control and the fractured site was fixed using finger bone plate with 4 screws, whereas the ear cartilage of $1 \times 1 \mathrm{~cm}$ graft was used to fill the gap after fracture fixation in Group II. Rabbits in two groups were subdivided into 2 subgroups of 1 and 2 months duration with 4 rabbits in each. Radiography and two dimensional and color Doppler sonography were done before and after creating defects and on 15, 30 and 60 days to evaluate local reaction as far as new blood vessels network and callus formation are concerned. Results: On the radiographs during the whole process, bone repair in Group I was not as perfect as those in Group II samples and trace of internal callus filled the gap incompletely in 60 days in Group I, whereas in Group II internal callus almost was formed on 30 days and in addition intercortical callus was seen supporting to cover and filled the gap completely in this group. Sonographic findings confirmed the protrusion of newly formed blood vascular network in 30 days in Group I and from 15 days in Group II and remarkably increased till end of observation period. Conclusion: Cartilage graft is suitable alternative bone filler and radiography and sonography are reliable techniques to trace local reaction at proper time.
\end{abstract}

Key words: Cartilage, sonography, radial bone, radiography, vascular network

\section{INTRODUCTION}

Although the skeleton is strong enough but occasional fractures has been reported many times. The healing processes of the fractures are main clinical problem in human and animals (Barden and Brinker, 1976; De Lutio di et al., 1993; Dickens et al., 1994; Fery-Lemonier et al., 1993; Anast et al., 1958; Friedrich and Volkenstein, 1991). Considering the nonhealing hypothesis and long term healings many investigations have been performed about the case in recent decades. The main attempts of these investigations were precipitation in healings, osteopathy and battening capability. In the last two decades osteografts and replacements in healing spongy bones and compact bones in osteopathy has prevail (Morgan and Leighton, 1997). Clinical consequences of grafts depends on many factors, such as grafts type, osteopexy and fracture position. All kinds of osteografts assimilate in body and assimilation processes in spongy bones are faster than compact bones. The most prevalent grafts are autografts, allograft, xenografts and synthetic substances. In spite of widespread osteobanks around the world there are still many questions about allograft immunology and repatternings to be answered. Many synthetics have developed in osteopathy and replacements. They had been used as implements in osteoectomy that investigated experimentally on animals (Toal, 1994). They enforce ossification, three dimensioned vascular genesis, capillary genesis and host intramembranous ossification in grafts. Considering restriction in replacements, it seems that using biological substances such as host cartilage tissue, fresh or reserved in limb banks should be examined in

Corresponding Author: Foad Sadi, Sciences and Research Branch, Department of Radiology, Faculty of Specialized Veterinary Sciences, Islamic Azad University, Punak, Tehran, Iran 
bones impairments, because of its osteogenesis capability and tissue interchanges. This investigation evaluates the cartilage grafts using sonographic and radiographic techniques.

\section{MATERIALS AND METHODS}

This study was performed in accordance with the Islamic Azad University Law on animal experimentation. Rabbits were treated accordingly to animal welfare legal regulations.

Sixteen adult male New Zealand rabbits having body weight from ranged from 3.5-3.0 Kg were given general anesthesia using combinations of acepromazine $1 \mathrm{mg} \mathrm{kgbw}{ }^{-1}$ intramuscularly as premedication (Karon Co. Iran) and anesthesia was induced intramuscularly using ketamine $35 \mathrm{mg} \mathrm{Kg}^{-1}$ (Alfasan WoerdenHolland) with combination of xylazine $5 \mathrm{mg} \mathrm{Kg}^{-1}$ (Afasan Woerden-Holland). Under restrict aseptic condition, skin incision was given on the latero medial surface of right radial bone and after separation of connective tissues and fascia a segmental full thickness bone defect of $10 \mathrm{~mm}$ in length was created in the middle of the right radial shaft in all rabbits (Fig. 1). They were divided into two groups of 8 rabbits each (Fig. 2). Group (I) was considered as control and the fractured site was fixed using finger bone plate with 4 screws, whereas the ear cartilage of $1 \times 1 \mathrm{~cm}$ graft was used to fill the gap after fracture fixation in Group (II) (Fig. 2). Rabbits in two groups were subdivided into 2 subgroups of 1 month and 2 months duration with 4 rabbits in each. Radiography and two dimensional and color Doppler sonography were done before experiment, after fixation and on 15, 30 and 60 days and interpretation were done by considering dislocation of graft, new-bone formation and new blood vascular network formation.

Post-operative care: Antibiotics, penicillin $\mathrm{G}$ procaine $40000 \mathrm{IU} \mathrm{kg}{ }^{-1}$, i.m. bid dexamethasone $0.6 \mathrm{mg} \mathrm{Kg}{ }^{-1}$, Vitamin B Complex $0.2 \mathrm{mg} \mathrm{Kg}^{-1}$ and analgesic agent such as Tramadol hydrochloride $5 \mathrm{mg} \mathrm{Kg}^{-1}$, i.m. bid were administered for 3 post-operative days. The lateral and cranio-caudal radiographs were taken before experiment, after fixation and on 15, 30 and 60 days:

- Radiographic evaluation was done using the healing indices such as:

- The probable inchoate internal callus

- The probable inchoate external callus

- The probable inchoate intercortical callus
- Osteo inductions in adjacent bones

- The amount of cartilage opacity in defective bone and its role in osteoconductivity during healings process

- The amount of healing callus in defective bones

- Sonographic evaluations were performed by Sonosite Titan Equipment. Linear probe in 10 Megahertz frequency and imbuing topical gel used in sonography

\section{RESULTS}

No operative or postoperative complications were encountered. All of the rabbits tolerated operation well and survived until the final study period. No wound opening or infections were observed. Radiographyically keeping in view the parameters were used to evaluate the major changes revealed no sign of infection on the edges of each defect and both groups permitted stabilization of the defected bones and maintenance of correct position. The new bone formation and local reaction in form of biodegradation of cartilage in the bone defects in Group II could be clearly reflected by the gradually replacing with new bone invasion. On the radiographs during the whole process, bone repair in Group I (Fig. 3) was not as perfect as those in Group II samples (Fig. 4, Table 1) and trace of internal callus filled the gap incompletely in 60 days in Group I, whereas in Group II internal callus almost was formed on 30 days and in addition intercortical callus was seen supporting to cover and filled the gap completely in this group (Fig. 5, Table 2). Sonographic findings confirmed the protrusion of newly formed blood vascular network in 30 days in Group I (Fig. 5, Table 3) and from 15 days in Group II and remarkably increased till end of observation period (Fig. 6, Table 4).

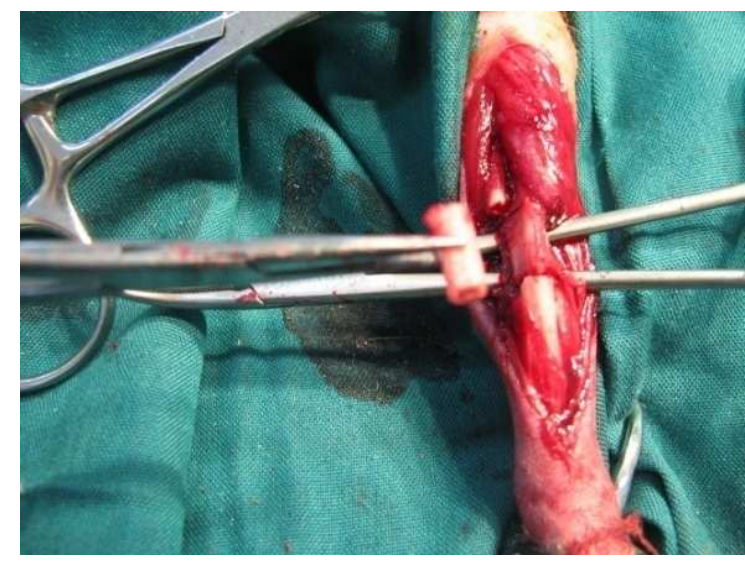

Fig. 1: Removal of cut piece of bone 
American J. Animal \& Vet. Sci., 5 (1): 40-44, 2010

Table 1: Radiographic findings in Group I at different intervals

\begin{tabular}{lllll}
\hline Day & 0 & 15 & 30 & 60 \\
\hline Soft tissue & Swelling soft tissue & Decrease of swelling soft tissue & No swelling soft tissue & No swelling soft tissue \\
Osseous & No internal callus & No internal callus & No internal callus & Internal callus \\
Tissue & No external callus & No external callus & No external callus & No external callus \\
& No intercortical callus & No intercortical callus & No intercortical callus & No intercortical callus \\
& To empty defect from callus & To empty defect from callus & To empty defect from callus & Relative to fill defect from callus \\
& No osteo induction & No osteo induction & No osteo induction & No osteo induction \\
\hline
\end{tabular}

Table 2: Radiographic findings in Group II at different intervals

\begin{tabular}{lllll}
\hline Day & 0 & 15 & 30 & 60 \\
\hline Soft tissue & Swelling soft tissue & Decrease of swelling soft tissue & No swelling soft tissue & No swelling soft tissue \\
Osseous & No internal callus & No internal callus & Internal callus & Internal callus \\
tissue & No external callus & No external callus & No external callus & No external callus \\
& No intercortical callus & No intercortical callus & No intercortical callus & Intercortical callus \\
& To empty defect from callus & To empty defect from callus & To empty defect from callus & Completely to fill defect from callus \\
& No osteo induction & No osteo induction & No osteo induction & No osteo induction \\
\hline
\end{tabular}

Table 3: Findings of two dimensional sonography and color Doppler in Group 1

\begin{tabular}{lllll}
\hline Day & 0 & 5 & 30 & 60 \\
\hline Ultrasonography & Defect: Hypo & Defect: Hypo & Defect: Increase & Defect: Increase \\
B-mode & echogenicity & echogenicity & echogenicity & echogenicity \\
Ultrasonography & Defect: No & Defect: No & Defect: Very small & Defect: Increase \\
color doppler & vascular blood & vascular blood & vascular blood & vascular blood \\
\hline
\end{tabular}

Table 4: Findings of two dimensional sonography and color Doppler in Group 2

\begin{tabular}{llll}
\hline Day & 0 & 15 & 30 \\
\hline Ultrasonography & Defect: Hypo & Defect: Increase & Defect: Increase \\
$\begin{array}{l}\text { B-mode } \\
\text { Ultrasonography }\end{array}$ & echogenicity & echogenicity & echogenicity \\
color doppler & Defect: No & Defect: Very small & Defect: Increase \\
vascular blood & vascular blood & echogenicity & Defect: Many \\
vascular blood & vascular blood \\
\hline
\end{tabular}

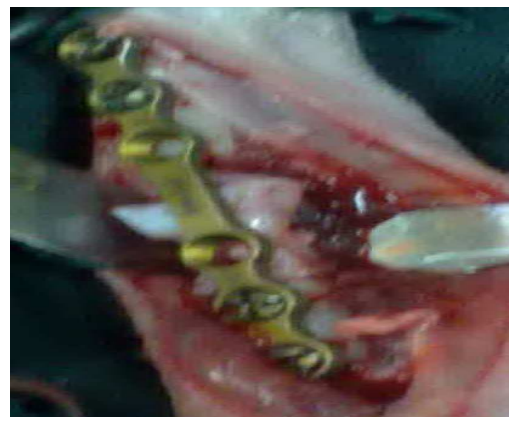

Fig. 2: Fixation of radial bone and packing of detect using ear cartilage

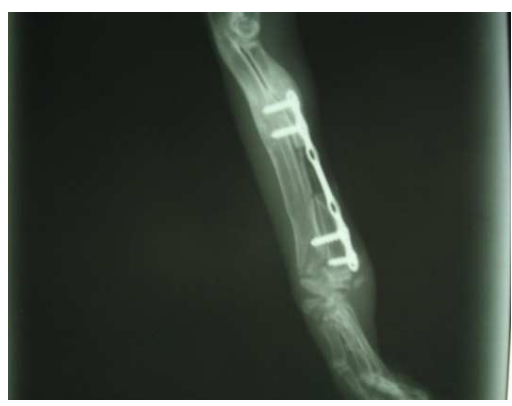

Fig. 3: Radiograph of control group at 60 days

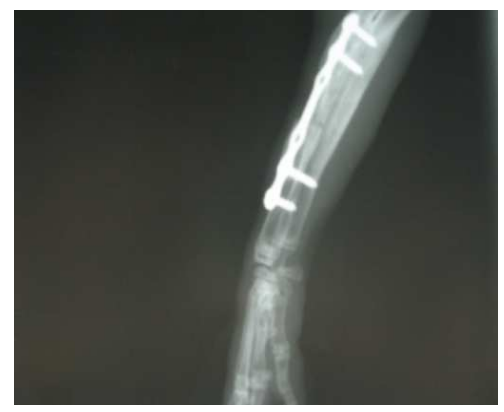

Fig. 4: Radiograph of group II at 60 days

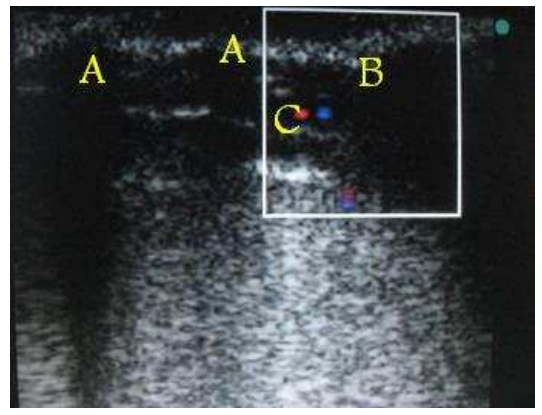

Fig. 5: Sonography of control showing (A) screw; (B) defect 


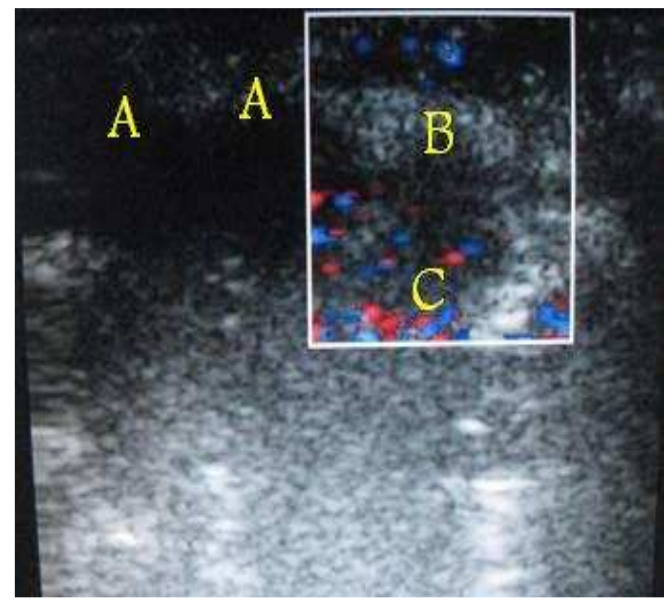

Fig. 6: Sonography of group II showing (A) screw; (B) defect

\section{DISCUSSION}

Radiology is a most important diagnostic test in the investigation of skeletal disease because good radiographic contrast is naturally provided between the bone and surrounding soft tissues permitted detection of rather small but clinically important changes (Barden and Brinker, 1976). Bone is a living system with number of functions and skeleton develops first as a cartilage model which is then replaced with bone by process of endochondral ossification (Mafulli et al., 1992; Sjostrom, 1998; Toal, 1994). As to evaluate the viability of biologically active freshly harvested ear cartilage as a graft to have dual role beside filling bone defect to stimulate and speed up healing capacity of fractured sites. In this study using freshly obtained cartilage tissue from the base of ear showed to have enough tough texture to be rolled and fill the gap without having any tendency to slip out. As per expected no local reaction was seen during first two weeks in both groups but sonographically sprouting small blood vessels network in Group II at end of two weeks in Group II with radiographic findings of intercortical callus formation within 30 days were good indication for local reaction of cartilage graft to act as stimulator to provide suitable bed for blood vessels penetration as compared to Group I (Graf et al., 1988; Hamanishi et al., 1994; Mende et al., 1986; Moss and Mowatt, 1983; Williamson et al., 1991) The ossification radiographically and pathologically being reported (Haktanir et al., 2005) in diced cartilage grafts used in cranial defects in rabbits. Findings of this study confirmed biological activity of cartilage despite of having self-blood vessels limitation. Using cartilage due to autogenicity, ease of shaping absence of post operative displacement and complication, inherent viability and ossification properties but slow in resorption rates will be a suitable biological graft for most of the lost fragments in skeletal system (Abiri et al., 1989; Eyres et al., 1993; Hamanishi et al., 1994). Despite of recommendation made for different synthetics materials to be used as a source of osteogenesis but the results of this study radio graphically and sonographically confirmed the positive local effects of ear cartilage as a bone filler and local stimulator to increase blood vessels and inner and intercortical callus formation. In conclusion. Investigators suggest the use of ear cartilage for local bone construction in which bone deformities may cause aesthetic and functional disabilities (Haktanir et al., 2005).

\section{CONCLUSION}

Cartilage graft is suitable alternative bone filler and radiography and sonography are reliable techniques to trace local reaction at proper time.

\section{REFERENCES}

Abiri, M.M., M. Kirpekar and R.C. Ablow, 1989. Osteomyelitis: Detection with ultrasound. Radiology, 172: 509-511.

Anast, T., T. Fields and I.M. Siegel, 1958. Ultrasonic technique for the evaluation of bone fractures. Am. J. Phys. Med., 37: 157-159.

Barden, T.D. and W.O. Brinker, 1976. Radhologic and gross anatomic evaluation of bone healing in dog. Journal of American Veterinary Medical Associations 169: 1318.

De Lutio di, C.E., B. di Maggio and S. di Gaeta, 1993. Echography in the monitoring of bone callus in fractures treated with external fixation. Radiol. Med., 85: 579-582.

Dickens, J.R., D.E. Bray and R.H. Palmer, 1994. An ultrasonic attenuation parameter for investigating the holding power of non-threaded fixation pins in vitro. Ultrasonics, 32: 65-70.

Eyres, K.S., M.J. Bell and J.A. Kaanis, 1993. Methods of assessing new bone formation during limb lengthening. J. Bone Joint Surg., 75: 358-364.

Fery-Lemonier, E., C. Roux, V. Hazebroucq, P. Legmann and C. Viens-Bitkern, 1993. Value of techniques of measurement of bone. Radiological methods and contribution of ultrasonics. J. Radiol., 74: 305-310. 
Friedrich, R.E. and R.J. Volkenstein, 1991. The value of ultrasonography in the diagnosis of zygomatic arch fractures. Dtsch. Z. Mand. Kiefer Gesichtschir, 15: 472-479.

Graf, M., V. Stahl-Kent, T. Ben-Ami, S. Strauss, Y. Amit and Y. Itzchak, 1988. Sonographic detection of occult bone fractures. Pediatr. Radiol., 18: 383-385.

Haktanir, A., O.A. Uysal and L. Yildiz, 2005. Radiologic and histologic assessment of diced cartilage graftd for cranial bone defects of rabbits: An experimental study. Aesthet. Plastic Surg., 29: 195-201.

Hamanishi, C., T. Yosii and S. Tanaka, 1994. Maturation of the distracted callus. Sonographic observations in rabbits applied to patients. Acta Orthopead. Scand., 65: 335-338.

Mafulli, N., T. Hughes and J.A. Fixsen, 1992. Ultrasonographic monitoring of limb lengthening. J. Bone Joint Surg., 74: 130-132.

Mende, U., K. Rieden, A. Braun, U. Weischedel and K.Z. Winkel, 1986. Die real-time-sonographie-Ein wichtiges bildgebendes verfahren bei Diagnostik und Therapieplanung von Skeettmetastasen. Ro. Fo., 145: 373-378.
Morgan, J.P. and R.L. Leighton, 1997. Radiology of small animal fracture management. WB Saunders Co. Philadelphila, 1995. 16. Piermattei DL. Small animal Orthopedics and Fracture Repair. WB Saunders CO. Philadelphia,

Moss, A. and A.G. Mowatt, 1983. Ultrasonic assessment of stress fractures. Br. Med. J., 286: 1479-1480.

Sjostrom, L., 1998. Ununited anconeal process in the dog. Vet. Clin. North Am. Small Anim. Pract., 28: 75 .

Toal, R.L., 1994. Fracture Healing and Complications. In: Textbook of Veterinary Diagnostic Radiology, Hn Thrall, D.E. (Ed.). WB Saunders Co., Philadelphia.

Williamson, S.L., J.J. Seibert, C.M. Glasier, R.E. Leithiser and J. Aronson, 1991. Ultrasound in advanced pediatric osteomyelitis. Pediatr. Radiol., 21: $288-290$. 